\title{
Cross-cultural Aspects of Academic Discourse
}

\begin{abstract}
This paper investigates cross-cultural aspects of academic discourse, exploring the complex nature of its realisations. Indeed, academic discourse is not at all uniform but varies according to a host of factors, such as language competence, local culture, disciplinary field, community membership, professional expertise and generic conventions. The data presented in this paper originate from a research project on Identity and Culture in Academic Discourse carried out by CERLIS, the research centre on specialised discourse based at the University of Bergamo. In this project special attention has been given to the relationship between socioculturally-oriented identity factors and textual variation in English academic discourse, focusing in particular on the identification of identity traits typical of different branches of learning. The data presented here show that the (native or non-native) Anglophone textual realisations taken into consideration are clearly influenced by their authors' cultural allegiance to their linguistic, professional, social, or national reference groups.
\end{abstract}

Key words

Academic discourse; cross-cultural aspects; journal editorials; book reviews; research articles

\section{Introduction}

In recent years, the weakening of national barriers, especially in the context of co-operation and collaboration at an international level, has accelerated moves towards the globalisation of socio-cultural and communicative practices. This globalising process has strongly favoured English, which over the last century or so has become the preferred medium for international communication in many contexts. This spread of English has had relevant ideological and ethical 
implications in the marginalisation, mitigation or even obliteration of existing differences among 'colonised' communities, thus preventing the attainment of authentic intercultural discourse (Scollon and Wong Scollon 1995; Canagarajah 1999). As globalising trends commonly rely on covert strategies meant to reduce participants' specificities, they hybridise local identities in favour of Anglocentric textual models.

Globalisation thus offers a topical illustration of the interaction between linguistic and cultural factors in the construction of discourse, both within specialised domains and in wider contexts (Candlin and Gotti 2004, 2007). As language is strictly linked to the setting in which it is used, cultural elements may operate as key contextual constraints, influencing both the level of discursive organisation and its range of realisations. Being associated with communities linked to local as well as international conventions, academic discourse has provided fertile ground for the analysis of intercultural variation, both at a textual level and in the communicative strategies embedded in its textualisations. Several research projects ${ }^{1}$ have investigated identity-forming features linked to 'local' or disciplinary cultures, as communicated through English in various academic domains by native and non-native speakers. By exploring the international perspective suggested by major social and academic actors, they have evaluated how far international audiences in key intercultural domains adopt textual reconfigurations that simplify, distort or even remove non-congruent institutional and cultural traits, while enhancing the identities of specific social and professional communities.

Academia is a field in which important changes due to globalising trends have emerged (Hyland 2000; Flowerdew 2002), with several cases of language variation linked to the encounter/collision of different cultural frameworks (Benesch 2001; Zamel and Spack 2001). The internationalisation of English academic discourse has not only been observed in Anglophone countries but wherever institutional and professional settings have evolved in ways that transcend the linguistic, cultural and conceptual standards of their local communities (Cotterill and Ife 2001; Candlin 2002). The gradual globalisation or hybridisation of discursive practices that first appeared in English-speaking environments, now significantly affects also smaller languages (Cortese and Riley 2002; Gotti et al. 2002), which are subject to standardising pressures in their semantic, textual, sociopragmatic and even lexicogrammatical construction.

The strict English-medium policies adopted by many academic publications and book series have aroused non-English-speakers' awareness that the increasing use of this language in publishing and higher education might greatly reduce the role of national languages for academic purposes. Indeed, as there is a tendency of scholars to publish what they consider to be their best work in English so as to reach a wider audience (cf. among others Gunnarsson 2000 for Sweden, Yakhontova 2001 for Ukraine, Salager-Meyer, Alcaraz Ariza and Zambrano 2003 for Latin America, Giannoni 2008 for Italy, Kachru 2009 for Asia and Ferguson et al. 2011 for Spain), non-English-medium publications are often relegated to the status of local scholarly products providing only a marginal contribution to the 
mainstream because they are unable to disseminate knowledge through a global lingua franca.

For some scholars (cf. Canagarajah 2002; Kandiah 2005) the considerable success of English in the world of academic research poses a threat not only to the survival and productivity of other languages but also for researchers from nonEnglish-speaking cultures, whose perception of specialised discourse inevitably diverges from the dominant Anglo-American model(s). In this sense, Mauranen (1993) claims that weaker academic discourses deserve attention and protection on a par with vanishing ecosystems, while Swales (1997) describes English as a tyrant in the field.

\section{Aims and corpus of analysis}

This paper investigates cross-cultural aspects of academic discourse, exploring the complex nature of its realisations. Indeed, academic discourse is not at all uniform but varies according to a host of factors, such as language competence, local culture, disciplinary field, community membership, professional expertise, gender and generic conventions. As a result, a wide range of features can be investigated as markers of authorial identity. Several studies have pointed out that, although different academic discourses have specific generic characteristics (Swales 1990, 2004; Bhatia 1993, 2004), they allow writers a certain degree of flexibility. At the same time, academic genres themselves are not stable but highly dynamic and closely related to their socio-professional contexts (Bhatia and Gotti 2006; Berkenkotter, Bhatia and Gotti 2012).

The data presented in this paper originate from a research project on Identity and Culture in Academic Discourse carried out by CERLIS, the research centre on specialised discourse based at the University of Bergamo. ${ }^{2}$ In this project special attention has been given to the relationship between socioculturally-oriented identity factors and textual variation in English academic discourse, focusing in particular on the identification of identity traits typical of different branches of learning. Within such domains, we have investigated to what extent the cultural allegiance of (native or non-native) Anglophone discourse communities to their linguistic, professional, social, or national reference groups is affected by the use of English as a lingua franca of international communication.

Early results from research carried out by our group of investigators indicated that the internationalisation which makes English the preferred choice of code is coupled with textual inconsistencies and ambiguities that advise against straightforward, simplified conclusions: the apparent dominance of 'Anglocentric' models in the domains considered reveals specific adaptive attitudes and evidence of cultural resistance in the textual strategies that construct identity-shaping differences. Our work has therefore moved in this direction, identifying cases of language variation linked to the encounter/collision of different cultural frameworks within English academic discourse. 
As corpora constitute a remarkable tool for the study of discourse, a specific corpus (Corpus of Academic Discourse, or CADIS) ${ }^{3}$ was assembled as the core and foundation of this line of research. In view of an in-depth analysis of variation in intercultural communication, we have selected a range of texts produced by scholars and academic institutions in various parts of the world. To identify textual variants arising from the use of English as a native language or as the lingua franca of science, we have used a corpus formed by English texts for academic communication. The corpus also comprises some Italian texts for comparative purposes. Besides including two different languages, CADIS represents four separate disciplinary areas: Law, Economics, Applied Linguistics and Medicine. For each disciplinary area, various textual genres have been considered. The structural complexity of CADIS reflects its contrastive orientation: it is designed to be internally comparable, so its texts can be analysed not only by disciplinary area, genre, language and culture, but also historically. This is possible because the corpus covers a time frame of over thirty years, from 1980 to the present day. Including all language groups - native speakers and non-native speakers of English, and native speakers of Italian -, a total of 2,738 texts (from 635 to 739 per disciplinary area) - have been inserted in the corpus so far. At present the corpus includes over 12 million words.

\section{Cross-cultural aspects in journal editorials}

Our research project has dealt with identity traits across languages and cultures, as the use of a given language affects the writing of a scholar, especially when it is not his native language. This is particularly evident in the case of English, whose recurrent use by non-native speakers requires a degree of adaptation of their thought patterns and expressive habits. These issues have been dealt with by various members of the CERLIS team. Giannoni (2012), for example, has investigated local vs. global identities in medical editorials. His analysis of AngloAmerican journals, English-medium Italian journals and standard Italian journals suggests a considerable extent of intradisciplinary variation, both within and across languages/cultures. The data investigated thus allow for the observation of the writing behavior of three different kinds of scholars: native-speaker English (NEng), non-native (i.e. Italian) English (ItEng) and native-speaker Italian (NIt) ${ }^{4}$ Since medical editorials (henceforth MEDs) are signed by only one or two authors, native-speaker status is relatively easy to determine, based on the author's name and affiliation.

A quantitative overview of the material (Table 1) shows interesting differences between the three sections in terms of average length, with NEng texts less than half the size of their NIt counterparts and ItEng somewhere in between. Discoursal complexity, as measured by average paragraph length, is instead greatest in NEng (44\% higher than NIt). These figures suggest that while Italian MEDs are lengthier than their native English counterparts, they organise the discourse 
into far shorter units. For both parameters, the ItEng group occupies the middle ground between the two.

Table 1. Average size of texts by section

\begin{tabular}{|l|c|c|c|}
\hline & Length (Tokens) & Range & Tokens/Paragraph \\
\hline NEng & 1,046 & $619-1,809$ & 125 \\
\hline ItEng & 1,882 & $609-3,637$ & 113 \\
\hline Nit & 2,429 & $1,154-5,222$ & 87 \\
\hline
\end{tabular}

Giannoni's analysis shows that editorialists employ three types of MED, whose prominence and microlinguistic traits vary across the corpus:

- Advice editorials are authoritative reviews of medical issues providing guidance for practitioners;

- Comment editorials are opinionated interpretations of developments affecting the medical community, with recommendations for action;

- Message editorials reinforce the journal's relationship with its readers, keeping them informed of its initiatives and developments.

While the orientation of the first subgenre is mainly teleological - i.e. driven by the need to shape medical practice - the second is evaluative and the third is phatic. A rough indication of the respective weight of these subgenres across the corpus is given in Table 2, which includes a fourth column, due to the presence in NIt of three spurious text types presented as editoriale (namely a review article, an essay and a conference talk). Interestingly, the three subgenres are documented across the corpus, with the sole exception of comment editorials. These are indeed the most variable subgroup, accounting for $80 \%$ of texts in NEng but none in ItEng. On the other hand, advice editorials are used far less, proportionally speaking, in NEng (10\%) than in the two groups authored by Italians.

Table 2. Proportion of MED subgenres across the corpus sample

\begin{tabular}{|l|c|c|c|c|}
\hline & Advice & Comment & Message & Other \\
\hline NEng & $10 \%$ & $80 \%$ & $10 \%$ & - \\
\hline ItEng & $60 \%$ & - & $40 \%$ & - \\
\hline NIt & $50 \%$ & $10 \%$ & $10 \%$ & $30 \%$ \\
\hline
\end{tabular}

These data warrant the hypothesis that Italian editorialists: (a) are less likely to comment on current affairs and issues of a (non-)medical nature, whether writing in their first language or in English; and (b) understand the 'Editorial' not only as a genre but also (in NIt) as a slot for publishing other genres that deserve editorial sanction.

Moreover, unlike their NEng counterparts, Italian writers are likely to incorporate references to their own work - a self-promotional strategy observed in all the ItEng texts and in $40 \%$ of the NIt sample. Italian scholars appear therefore 
to be freer in their use of the MED genre, with no clear-cut distinction between the role of editorialist (knowledge validation) and that of researcher (knowledge construction). The high rate of self-citations in ItEng indicates that the two functions are particularly blurred when editorialists address an international audience through the medium of English.

One notable difference between the NEng texts (e.g. quotation 1) and the other two groups (e.g. quotations 2 and 3 ) is (with only one exception) the absence among the latter of direct appeals to the medical community. When a course of action is advocated, as in (3), its wording is both impersonal and indirect. Viewed contrastively, this difference may reflect the more tentative orientation of NIt MEDs (rhetorical interference) but also - more intriguingly - greater interpersonal distance in the ItEng sample, where local (Italian) academics address a global community of which they are, linguistically speaking, only peripheral members.

(1) We still have hurdles of ethics, immunology and biology to conquer, and until we do, we must remain on guard against donor scotoma. (NEng, MEED494)

(2) Therefore, we believe that right insula activation has a significant role in the perception of chest pain in syndrome $\mathrm{X}$ (the insula is known to receive cardiopulmonary inputs). (ItEng, MEED511)

(3) Tale strategia può contribuire a ridurre in maniera significativa il rischio di reazioni avverse a farmaci idrosolubili e i costi sanitari ad esse correlati [This strategy may help to significantly reduce the risk of adverse reactions to hydrosoluble drugs and their associated healthcare costs]. (NIt, MEED916)

Comment editorials were the second most common type of MED but also that with the greatest range of variation across the corpus, accounting for $80 \%$ of NEng, $10 \%$ of NIt and none of the ItEng texts. Interestingly, all the NEng instances come from the oldest, most firmly-established publication in the corpus (Journal of Clinical Investigation). This suggests that critical commentaries are more likely to originate from Anglo-American contexts, where the editorial stance of certain journals allows a high level of 'militancy'.

The purpose of message editorials is essentially phatic, insofar as they seek to forge/maintain a strong relationship with the readership by keeping it informed of editorial decisions and policies. Consequently, editorialists act here in an institutional as well as an individual capacity. Altogether, this was the least common MED subgenre observed in the corpus, accounting for only $10 \%$ of texts in NEng and NIt. The figure rises to $40 \%$ in the ItEng group - which suggests that the effort to engage readers overtly is greatest for English-medium publications originating from the periphery. In ItEng, however, message editorials are always metatexts introducing/promoting the journal's advice editorials. The different use 
of message editorials across the CADIS sample is clearly observable in their macrostructure. The two texts in NEng/NIt are essentially unstructured narratives bringing to the attention of readers important developments in the journal's life (and/or that of its affiliates). Such MEDs span events in the past, present and near future, as shown by the following excerpts:

(4) The wind of change is in the air again. The British Journal of Plastic Surgery is a great and almost a venerable title, but it seems that BJPS can never stand still. [...] Many of our readers are discovering the benefits of Science Direct, which carries the full text of BJPS from the very first issue, available on line and fully searchable through hypertext links. [...] Now, from January 1st 2006, our journal will become JPRAS, The Journal of Plastic, Reconstructive and Aesthetic Surgery, and will be published every month. (NEng, MEED498)

(5) Con questo numero, l'Italian Heart Journal diviene organo di stampa anche della Società Italiana di Chirurgia Cardiaca. [...] È ormai nei fatti della nostra attività clinica quotidiana il sempre più stretto legame e la proficua integrazione di competenze tra specialisti cardiologi e cardiochirurghi. [...] L'Italian Heart Journal avrà un compito importante ed impegnativo nel sostenere le sempre più numerose iniziative che le Società di settore stanno cercando di portare avanti. [With this issue the Italian Heart Journal becomes an official publication of the Italian Heart Surgery Society. [...] Our daily clinical practice already bears witness to the ever closer link and fruitful integration of competences between heart specialists and heart surgeons. [...] The Italian Heart Journal will face the important and challenging task of supporting the increasing number of initiatives that medical societies are attempting to conduct.] (NIt, MEED907)

Giannoni's analysis thus shows that, as a consequence of the composite generic profile of the medical editorials analysed and of the co-existence of no less than three distinct subgenres (Advice, Comment, Message), editorialists are keen to adapt their voice to the specific communicative purpose text, taking on a different identity and evaluating a different target, as summarised in Table 3:

Table 3. Generic profile of medical editorials

\begin{tabular}{|l|l|l|}
\hline Subgenre & Voice & Target \\
\hline Advice & Expert & Disciplinary Knowledge \\
\hline Comment & Journal & World \\
\hline Message & Editor & Journal and Editor \\
\hline
\end{tabular}

Moreover, the multilingual and multicultural environment in which scholars are working within a globalised context implies the fact that editorialists are faced with the challenge of reconciling two 'small cultures' (their local academic com- 
munity and lingua-cultural affiliation) with a 'large culture' (the discipline as a global, translinguistic community). The easy option is to concentrate on the latter, forgetting that it can only emerge through a negotial process involving the former. Italian scholars appear to be avoiding this risk and draft English editorials that do not merely incorporate elements of the Native English / Native Italian repertoire but do so in innovative and at times creative ways.

\section{Cross-cultural aspects in book reviews}

In her analysis of book reviews (BRs) written in English and Italian by native (NSs) and non-native speakers (NNSs), D'Angelo (2012) has investigated how reviewers of different nationalities, within the disciplines of Applied Linguistics, Economics, Law and Medicine, express positive and negative appraisals (respectively PAs and NAs) of their peers' work. The comparison of the English and Italian sections of the corpus has shown that in all the disciplines considered in the study, BRs written in English are generally much longer than BRs written in Italian (Cf. Table 4). One factor of a quantitative nature could account for the greater variation in length observed in Italian and English BRs: in every discipline different journals impose different word limits on BR writers. However, there seem to be different cultural norms and traditions when it comes to producing BRs for Italian journals. In the discipline of Applied Linguistics, Economics and Law, all of the Italian journals limited the amount of words (and therefore the space and depth) of BRs. The biggest difference in the average length of texts is found in the discipline of Law, where Italian BRs are ten times shorter than the English ones, and in the discipline of Applied Linguistics, where Italian BRs are four times shorter than the English ones. In Medicine instead, BRs are found to be of the same length, and therefore the 'cultural' trend of limiting the use and space of BRs does not seem to apply to this discipline.

Table 4. Corpus size

\begin{tabular}{|l|c|c|c|c|c|c|}
\hline \multirow{2}{*}{} & \multicolumn{3}{|c|}{ ENGLISH } & \multicolumn{3}{c|}{ ITALIAN } \\
\cline { 2 - 7 } & $\begin{array}{c}\text { Running } \\
\text { words in } \\
\text { subcorpus }\end{array}$ & $\%$ & $\begin{array}{c}\text { Average } \\
\text { length of BR }\end{array}$ & $\begin{array}{c}\text { Running words } \\
\text { in subcorpus }\end{array}$ & $\%$ & $\begin{array}{c}\text { Average } \\
\text { length of BR }\end{array}$ \\
\hline $\begin{array}{l}\text { Applied Lin- } \\
\text { guistics }\end{array}$ & 48,521 & 24.7 & $1,617.3$ & 4,842 & 19.8 & 372.4 \\
\hline Economics & 36,173 & 18.4 & $1,205.7$ & 6,074 & 24.8 & 467.2 \\
\hline Law & 89,322 & 45.6 & $2,977.4$ & 3,635 & 14.8 & 279.6 \\
\hline Medicine & 22,016 & 11.3 & 733.8 & 9,964 & 40.6 & 766.4 \\
\hline Total & 196,032 & & & 24,515 & & \\
\hline
\end{tabular}

The second aspect is rhetorical and consists in the fact that English-speaking book reviewers tend to expound their own views, including, of course, their discrepancies not only with the book they are reviewing, but also with certain beliefs 
held by the scientific community at large. An example of such rhetorical device found in a BR written by a NS is provided hereafter:

(6) A\&C's appeal to 'identity' misrepresents the language-ideological climate in contemporary Wales. Coincidentally, colleagues and I have substantial recent data (e.g., Coupland, Bishop, Evans \& Garrett, in press) showing that Wales already benefits from strongly positive and widely distributed pro-Wales and pro-Welsh ethnolinguistic subjectivities. (ALBR614, emphasis added as in all the other quotations in this paper)

In this case the reviewer does not only express his opinion on a subject, but also offers his own research findings and data to sustain his comment, a typical feature taken over from the research article genre. Italian BRs instead are very often just a brief summary of the book itself and contain very brief comments from the reviewer.

If we concentrate on BRs written in English (Table 5), an interesting finding is that in all four disciplines considered, NNSs seem to produce slightly longer BRs than NSs.

Table 5. Running words in BRs written in English by NS and NNS

\begin{tabular}{|l|c|c|r|}
\hline \multicolumn{2}{|c|}{} & Average length of English BRS & $\%$ \\
\hline \multirow{2}{*}{$\begin{array}{l}\text { Applied } \\
\text { Linguistics }\end{array}$} & $\mathrm{NS}$ & $1,568.4$ & 12.3 \\
\cline { 2 - 4 } & $\mathrm{NNS}$ & $1,666.2$ & 12.9 \\
\hline \multirow{2}{*}{ Economics } & $\mathrm{NS}$ & 1,016 & 7.9 \\
\cline { 2 - 4 } & $\mathrm{NNS}$ & 1,397 & 10.8 \\
\hline \multirow{3}{*}{ Law } & $\mathrm{NS}$ & $2,843.2$ & 22 \\
\cline { 2 - 4 } & $\mathrm{NNS}$ & $2,945.5$ & 22.9 \\
\hline \multirow{2}{*}{ Medicine } & $\mathrm{NS}$ & 652 & 5 \\
\cline { 2 - 4 } & $\mathrm{NNS}$ & 790 & 6.2 \\
\hline
\end{tabular}

Also Rowley-Jolivet and Carter-Thomas (2005: 45) found that clauses in NNS texts (research articles and paper presentations) are considerably longer than in NS texts, something accountable to the more frequent use of the passive form by NNSs than by NSs, which leads to the production of longer, more articulated sentences.

D'Angelo's analysis has revealed that in general, in English and Italian book reviews, PAs are much more frequent than NAs. More specifically, in the English book reviews analysed, NAs amounted to only $36.2 \%$, whereas PAs amounted to $63.8 \%$. As far as the Italian corpus is concerned, NAs only amounted to $16.5 \%$, whereas PAs amounted to $83.5 \%$. The fact that in Italian BRs there are many more PAs (83.5\%) than in the English BRs (63.8\%) seems to indicate that Italian book reviewers are not very critical and judgmental towards their peers. Rather, they tend to favour collegiality instead of trying to strike a balance between praise and criticism, as their English colleagues do. Their texts are, in most cases, plain 
summaries of books and seem to be more neutral and objective descriptions of the contents than critical analyses.

The analysis also reveals that a difference exists between NS and NNS in their use of appraisals. Specifically, NS seem to use PAs slightly more than NAs (49.2 vs 31.3), whereas NNS use twice as many PAs as NAs (40.4 vs 20). More important is the fact that in general, NS seem to make a much more frequent use of appraisals: the number of NAs found in texts written by NS is 31.3 , whereas the number of NAs found in NNS texts is only 20; along the same line, the number of PAs found in NS texts is 49.2, while the number of PAs found in NNS texts only amounts to 40.4 . These results suggest that although reviewers in general prefer giving positive feedback, NNSs are less likely to judge another colleague's work negatively and express less evaluation than NSs do.

The investigation of different disciplines has shown that the use of PAs and NAs is surprisingly consistent: PAs are always used at least twice (if not three times) as often as NAs. What is interesting to note is that in Law, English reviewers evaluate a book negatively much more frequently than in other disciplines (cf Table 6). Reviewers in Economics also use NAs frequently in comparison with other disciplines, whereas in Medicine, they do so much more rarely. When we consider the use of appraisal in Italian, we cannot but notice that the only reviewers that try to reach a balance between positive and negative evaluations are the ones working in the field of Economics (7.3 NAs vs. 13 PAs). On the contrary, the authors who use NAs the least and are undeniably much more prone to positive peer reviewing, are the ones writing in Law (2.8 NAs vs. 37.5 PAs).

Table 6. Occurrences of NAs and PAs in different disciplines

\begin{tabular}{|l|c|c|c|}
\hline \multirow{4}{*}{ APPLIED LINGUISTICS } & & NA & PA \\
\cline { 2 - 4 } & ENG & 10.1 & 15 \\
\cline { 2 - 4 } & ITA & 7.7 & 28.9 \\
\hline \multirow{3}{*}{ ECONOMICS } & ENG & 12.8 & 22.6 \\
\hline \multirow{2}{*}{ LAW } & ITA & 7.3 & 13 \\
\hline \multirow{2}{*}{ MEDICINE } & ENG & 22.9 & 36.4 \\
\cline { 2 - 4 } & ITA & 2.8 & 37.5 \\
\cline { 2 - 4 } & ENG & 5.5 & 16.2 \\
\cline { 2 - 4 } & ITA & 4.4 & 27.3 \\
\hline
\end{tabular}

If in every discipline we further differentiate between native and non-native reviewers, we notice that the use of NAs and PAs follows a clear pattern: every discipline considered sees NNSs consistently using almost twice as many PAs as NAs (cf. Table 7). These data further validate the hypothesis that NNSs, in every discipline, tend to use evaluation less frequently and, most of all, they tend to prefer evaluating positively rather than negatively. 
Table 7. Occurrences of NAs and PAs in different disciplines, by NS and NNS

\begin{tabular}{|l|l|c|c|c|}
\hline \multirow{2}{*}{ APPLIED LINGUISTICS } & & NA & PA \\
\cline { 2 - 5 } & \multirow{2}{*}{ ENG } & NS & 8.1 & 10.1 \\
\cline { 3 - 5 } & & NNS & 4.9 & 6.7 \\
\hline \multirow{2}{*}{ ECONOMICS } & \multirow{2}{*}{ ENG } & NS & 8 & 15.2 \\
\cline { 3 - 5 } & & NNS & 4.7 & 7.3 \\
\hline \multirow{2}{*}{ LAW } & \multirow{2}{*}{ ENG } & NS & 11.3 & 16 \\
\hline \multirow{2}{*}{ MEDICINE } & \multirow{2}{*}{ NNS } & 6.8 & 25 \\
\cline { 3 - 5 } & ENG & NS & 3.6 & 12.5 \\
\hline
\end{tabular}

If we consider how hedged NAs are used in BRs, relevant differences appear among the writers depending on whether the author is an Italian or English speaker. Specifically, hedges are more frequent in NS English than in Italian, the former totalling 13.1 instances, the latter merely 9.3. However, an even wider difference is detected when considering the use of hedges by NS and NNS of English, the former using five times more hedges (13.1) than the latter (2.6). These results are probably related to the fact that in general Italian and NNS reviewers use evaluation much less frequently than English L1 speakers. In the English texts, the mitigation of negative evaluative acts is realized in various ways. The following are examples of some of the strategies found in the corpus: the labelling of a criticism as a personal opinion (7), the attribution of critical comments to an abstract reader (8) or a general audience (9) and the use of metadiscourse to announce the presence of criticism in the text (10).

(7) Given M's focus on social class, I would have appreciated more discussion of class in Scotland by M, and more analysis in chapter 10 of the ideology of social class. (ALBR698)

(8) One gets the impression that Estrada is focusing more on Sonora usage, than on Arizona. (ALBR683)

(9) These sections are rigorous, yet the reader is left wondering why the other three approaches are included at all as they seem almost superfluous. (ALBR683)

(10) The authors rightly acknowledge that journal articles reporting on qualitative studies do not always include details of the coding process. Nevertheless, it is odd that one such study was selected as the example. (ALBR657)

In the Italian texts, the instances of hedging found in the corpus see the use of the conditional and contrastive transitions: 
(11) Nonostante le ottime citazioni presenti nel volume, esso avrebbe potuto contenere maggiori esemplificazioni. [Despite the excellent citations in the volume, it could have provided more examples.] (ALBR823)

(12) Tuttavia l'elenco avrebbe potuto essere sfrondato di molte forme derivate, quali smartelà 'martellare' (p.165), la cui etimologia non è diretta, ma mediata dalla forma base martèl, e magari arricchito con la trattazione di altre parole esclusive del bergamasco. [However, the list could have been stripped of many derivative forms, such as smartelà 'hammering' (p.165), the etymology of which is not direct, but mediated by the basic form martèl, and perhaps enriched with the treatment of other words exclusive of Bergamo's dialect.] (ALBR836)

D'Angelo's study confirms the great evaluative value of book reviews, as these provide an important forum for discussion as well as a particularly fertile ground for research. Moreover, her analysis shows that critical speech acts tend to be language/culture dependent and that a reviewer's pragmatic-rhetorical choices are indeed influenced by his/her cultural identity.

\section{Cross-cultural aspects in research articles}

Maci (2012) has compared the argumentative strategies employed in medical research articles (RAs) written by native speakers of English with those written by Italian non-native speakers of English in order to identify any cross-cultural differences in terms of argumentative devices employed by their authors. Analysing the Discussion section of 50 articles from two important journals of cardiology - the Italian Heart Journal (published in English) which, in 2006, changed its name to the Journal of Cardiovascular Medicine, ${ }^{5}$ and the American journal Circulation -, she has identified several differences between the textual organization of English medical research articles written by native and non-native speakers, which seem to be linked to their authors' linguistic and cultural identity. The main differences are rhetorically realised through hedges and other argumentative strategies, such as the use of connectives. Indeed, NSs of English tend to exploit more fully modality expressed by modal auxiliaries (such as may, would), verbs (such as appear, suggest), and adverbs (such as likely). The modal verb may, in particular, frequently appears in the NSs corpus, to such an extent that it can be regarded as a keyword with high keyness (may occupies position 15). This is not the case in the Italian NNSs subcorpus, where may occupies position 95.

The minimal use of hedges in the Italian NNSs subcorpus seems to be counterbalanced by other grammatical devices: whenever the outcome conforms to the expected results and is thus validated, Italian authors tend to interpret outcomes with the use of the present tense of such boosters as confirm, find and show rather than using hedging devices. If hedges are used, there is a preference for might, which may be perceived by NNSs as carrying a stronger connotation of probability than may, or 
should, employed whenever a suggestion about the correct scientific procedures and/ or treatment is made. This occurs especially whenever the results do not confirm the initial hypothesis, or whenever there is a gap in the existing literature filled by the present research. In these cases, NNSs of English seem to prefer the use of hedges and modal expressions to indicate probable interpretations or possible implications:

(13) In our opinion, aortic plaques are those the most likely to be responsible for recurrent cerebral events. Furthermore, aortic atheromatosis should be considered as a clinical entity itself and should be related to different vascular districts than the cerebral one. This was demonstrated in a study by Pandian et al. [46], who affirmed that [...]. (MERA242)

(14) Although no complications occurred in any patient implicating the safety of cryoenergy, these results are slightly inferior to what can be expected with RF energy in terms of acute success. In 17 patients (nine AVNRTs, eight APs) out of 126 patients $(13 \%)$ with acute successful ablation, recurrence of the arrhythmia and/or AP was observed. The percentage of recurrence is therefore higher than that usually reported with RF energy [...]. The high rate of recurrences in this series may be ascribed to a possible more limited lesion created by cryoenergy, which can even further decrease in dimensions in the early post-ablation phase owing to tissue healing. (MERA250)

The scarce use of hedges is mitigated by the presence of supporting evidence provided by previous studies in the same field, with quotations employed so as to establish academic credibility. References are inserted as matter-of-fact, thus making them more certain and strengthening the case made. Results are therefore made meaningful because researchers refer to previous accounts of formal research. Furthermore, quotations are not listed as anonymous numbers; rather, they are personified by quoting the surname of the author(s) of previous studies.

A further differentiation can be seen in the use of connectives. There is a lower frequency of connectives in RAs written by NNSs of English, which seems to reflect the trend already established by Italian authors as far as the use of hedges is concerned: whenever the claim is confirmed and supported by scientific literature in the field, Italian researchers seem less keen on exploiting argumentative strategies, as, apparently, reference to the literature becomes the objective evidence supporting the author's reasoning. For instance, the concordance list of also shows a different distribution of the connective: in the NSs subcorpus it is mainly used to underline the findings resulting from the investigation, which may confirm the researcher's hypothesis; in the NNSs subcorpus, also is found in connection with reference literature supporting the researcher's data:

(15) $[\ldots]$ the immediate postoperative period also demonstrated that the combination of clopidogrel and aspirin was more effective than aspirin alone in reducing MES. (MERA204) 
(16) Moreover, BNP is a strong predictor of mortality not only due to heart failure progression $_{35-37}$ but also to sudden death. ${ }_{38}$ (MERA228)

The more frequent use of although, furthermore, hence, in contrast and therefore in the NSs subcorpus is indicative of the presence of a textual organization in which scientific information is offered in a coherent and convincing way. Here, the problematizing proposition is introduced by although, which positions the reader in the correct reasoning path: although presupposes the presence of a second part of a sentence which the reader expects to carry the right type of information necessary to decode the semantic value offered by the researcher's investigation:

(17) Although sharing a common familial environment may inflate the estimates of heritability, we found low to moderate heritability for BMI, which in turn represents the maximal possible contribution of additive genes. (MERA209)

In the NNSs subcorpus, the extremely high frequency of such connectives as on the contrary and on the other hand seems to suggest a preference for a type of argumentation in which the author plays with a twist: first there is the introduction of common shared knowledge (and reference literature); then there is a counterclaim, from the author's research, supported by other cited literature. This is further emphasised by a list of evidential elements (and relevant literature), introduced by first, second, third, etc. which support the results of the researcher's investigation, as in (18):

(18) First, with respect to infero-posterior AMI, where sympathetic activation may follow transient signs of vagal hyperactivity ${ }_{20,21}$ anterior AMI is constantly followed by strong and stable signs of enhanced adrenergic tone; ${ }_{20}$ thus, we avoided any potential flaw in the interpretation of the changes in vagal and sympathetic effects. In addition, the effects of cardiac rehabilitation have been extensively studied in patients with anterior myocardial infarction and reduced ejection fraction in whom concern for adverse ventricular remodeling has been expressed. ${ }_{22,23}$ (MERA234)

Italian authors seem therefore to prefer the use of an ipse-dixit strategy: whenever a claim finds confirmation in the existing literature, they tend to adopt rhetorical strategies less frequently because the established knowledge is deemed to be sufficient to confirm their hypothesis.

\section{Cross-cultural aspects in legal articles}

Sala (2012) has investigated the different rhetorical styles and strategies employed by native and non-native speakers of English, and by experts of Common Law (henceforth indicated as CoL) vs. experts of Civil Law (CiL) systems when discussing legal subjects. By comparing articles authored by native and non-na- 
tive speakers, Sala shows that the two groups of experts express their identity and stance differently, with argumentative-persuasive strategies influenced by the different philosophies behind the two legal systems - i.e., the adversarial vs. the inquisitorial approach, the principle of precedent vs. recourse to the civil code, the primacy of witness examination vs. the primacy of written norms and abstract principles. This differentiation is particularly noticeable in the use of such metadiscursive interactive and interactional resources as personal pronouns, markers of epistemic modality and interrogative forms. Moreover, variations were also found in terms of text orientation (knowledge-oriented vs. reader-oriented), level of informativeness (explicitness vs. implicitness) and degree of cooperation (inclusiveness vs. exclusiveness, assertive vs. defensive strategies).

As regards the use of first person pronouns and possessives, their presence is quite remarkable both in the $\mathrm{CiL}$ and in the CoL sub-corpora. In general, $\mathrm{CoL}$ experts use personal references more frequently than CiL scholars, both singular (31.5 vs. 17.1) and plural (19.6 vs. 9.6). However, in CiL texts the first person singular is concentrated in the opening sections, whereas other pronouns (i.e., the first person plural, or impersonal constructions) are used in the discussion sections. A less marked distinction between singular and plural forms is featured in CoL texts, where authors combine the use of I (me, my) and we (us, our) within the same text in conventional expressions like I believe, in my view, as we will see, we can say, etc. Moreover, $\mathrm{CoL}$ authors use reader-inclusive strategies more often than their CiL colleagues $(80.3 \%$ of the total plural occurrences vs. 61.7 $\%$ ) who instead resort to reader-exclusive strategies twice as often as CiL experts (38.3\% vs. $19.7 \%)$.

Reader-inclusiveness, implicit in some uses of the first person plural, can be further enhanced either by directly resorting to the second person pronoun and possessive, or by employing interactional strategies like interrogatives and imperatives, which are reader-in-the-text resources (Thompson 2001) meant to rhetorically represent the reader in the discourse. This strategy is fairly common in the CADIS legal sub-corpus, as opposed to the use of the second person pronoun, which is quite infrequent and limited to conventional expressions (e.g., if you will, as you will see, etc.). Imperatives are emphatic attention-seeking devices and may have different pragmatic functions, such as furthering the discussion of given points (i.e., see, consider, note, as in (19)) or introducing a new line of argumentation or a different perspective (i.e., suppose, imagine, cf. (20)).

(19) The board of the foundation was to be elected from the group of guarantee capital owners at the time when the savings bank was converted into a corporation (this was changed later - see below). (LARA259)

(20) For example, imagine a contract between an automobile manufacturer and a supplier of car bodies; in the contract a certain number of car bodies may be fixed. Now, the demand for automobiles may rise and the manufacturer wants to increase the supply of car bodies. (LARA264) 
Similarly, questions are a direct appeal to the reader and are meant to engage the audience in active reasoning (Harris 1984, Pascual 2002, 2006). They have two main functions: a) a textual function, to signal either the overall cognitive organization of the material or the nodal and salient points of the argument, in order to facilitate the reading process $(21)$; b) an evaluative-rhetorical function, meant to anticipate and respond to possible objections or to emphasize paradoxes so as to construct common grounds with the readers (22).

(21) Can we therefore make a distinction between de jure organs, i.e. organs within the meaning of Article 4, and de facto state organs, i.e. persons or entities which for all intents and purposes act as state organs, even though that status is not recognized by the internal law of the state? In other words, can a state escape responsibility merely by shielding the acts committed by its $d e$ facto organs through the deceptions of its own internal law? The ILC Commentaries quite rightly answer this question in the negative. (LARA210)

(22) The evidence is right there before us. In the absence of such tangible evidence, can we rely on the law enforcement officials in the victim state to 'convict' persons of planning terrorist attacks? Should we not fear that this limited 'exception' may be exploited and abused by states eager to turn the struggle against terrorists into all-out war? (LARA209)

The results of the frequency counts show that CoL experts are more at ease than CiL experts in using the second person. More specifically, the analysis reveals that, with very few exceptions, CiL writers use the second person predominantly in conventional expressions (e.g., as you will see, if you will, etc.), whereas CoL experts combine conventional expressions with more creative ones, or exploit it in hypothetical clauses (e.g., if you were to..., suppose that you..., etc.). Moreover, imperative forms - with the sole exception of let - are on the whole more frequently found in the CoL sub-corpus. The data also indicate that the most typical imperative forms appearing in legal studies are those which are meant to challenge the audience towards using active mental processes: verbs requiring the reader to consider new scenarios and different points of view (e.g., imagine, suppose) are more frequent in CoL than in CiL texts (58.2\% vs. $14.2 \%$ for imagine, $26.5 \%$ vs. $14.3 \%$ for suppose). Finally, Sala points to two different trends as to the use of interrogatives: on the one hand, CiL writers seem to prefer questions with a textual function, thus merely indicating the general or sequential organization of the argument; on the other hand, CoL experts tend to engage their audience in more active reasoning through rhetorical and evaluative interrogative structures which question assumptions, elicit doubts or emphasize informative gaps, and subsequently provide all the necessary information to infer the most suitable answer.

Sala's analysis of the interactive-dialogical dimension of the argumentation and the varying level of assertiveness in the expression of interpersonal meaning has led him to trace some interesting patterns of differentiation between the 
$\mathrm{CiL}$ and $\mathrm{CoL}$ subcorpora. In general, $\mathrm{CoL}$ writers tend to exploit interaction and personalisation, and use a tentative mode of argumentation, while CiL experts generally resort to a more detached style and to a more assertive and confident tone. Both tendencies can be meaningfully interpreted in relation to the forensic expertise of the authors. In fact, the CoL system - adversarial by definition - is eminently interactive, directly involving the prosecution and the defence, as well as the judge and the jury, who have the prominent role of implied and privileged audience for all courtroom monologues. Thus all resources meant to engage the listener in active reasoning and to focus their attention on the salient stages of the argumentation play a key role in CoL forensic practice. On this basis, the recourse to the second person pronoun, especially in its non-conventional use (i.e. for exemplification purposes), the remarkable number of rhetorical questions, and the creative use of imperatives to attract the attention of the readers can be interpreted as a distinctive trait of $\mathrm{CoL}$ forensic argumentation in academic discourse.

The CiL system is instead inquisitorial, and hinges heavily on the prominent role of the judge, the written testimony, and the principle of non-negotiable truth. As a consequence, lawyers are more accustomed to less interactive contexts. The familiarity with this juridical philosophy and its forensic practice may account for the limited personalisation found in RAs authored by CiL writers, which leads to the use of the personal pronoun we with a reader-exclusive function and to second person interactional strategies such as imperatives. The latter are here usually employed for their highly conventionalized discursive function as mere textual indications but are devoid of any specific engaging purpose. Along the same line, the limited number of rhetorical and evaluative questions in this sub-corpus, which is distinctive of CoL practice and CoL RAs, is a trace of the detached and de-personalized style expected in CiL forensic contexts.

\section{Conclusion}

As shown by the investigations of the CADIS corpus analysed in this paper, our purpose was to better understand how and to what extent language forms and functions are adapting to the globalisation of academic discourse. Our findings show that one of the key factors of verbal behaviour is the affiliation of actors to one or more cultures (whether professional, ideological, or ethnic-geographic); this does not only affect a discourse community's thinking and internal relationships but also the rhetorical 'positioning' of its participants. Moreover, the studies reported here also reflect the considerable challenges and opportunities that confront scholars seeking to achieve a delicate balance between their willingness to adhere to the norms and conventions of their professional community and the desire to express individual values and identity traits. Such factors have been found to interact, producing transversal identities that often betray their dependence on local traits and traditions, thus giving rise to textual realisations characterised by hybridising forms deriving from intercultural clashes. 


\section{Notes}

1 Two recent projects on this issue are the KIAP Project (Cultural Identity in Academic Prose, $<$ http://www.uib. no/kiap/>), carried out by the University of Bergen, Norway, and the SERAC Project (Spanish/English Research Article Corpus), conducted at the University of Zaragoza $(<$ www.interlae.com $>)$.

2 Some of the results of this research project have been published in Gotti (2012).

3 A breakdown of the CADIS corpus is available online at $<$ www.unibg. it/cerlis $>$.

4 The journals investigated are as follows: British Journal of Plastic Surgery and the US-based Journal of Clinical Investigation for NEng; English editorials from two bilingual journals, the Italian Heart Journal and Epidemiologia e Psichiatria Sociale, for ItEng; the Giornale Italiano di Cardiologia (GIC) and Recenti Progressi in Medicina (RPM) for NIt.

5 Since, in Italy, Italian journals, despite their in-depth analyses, are regarded as second-class research tools by the local medical community, and since medical journals are regarded as being serious only if they are published in English, either in the UK or in the US, the Italian scientific board of the Italian Heart Journal decided to conceal the Italian-like quality of the journal by assigning it an English name (Journal of Cardiovascular Medicine) and an American publisher, whilst maintaining an Italian editorial and scientific board.

\section{References}

Benesch, Sarah (2001) Critical English for Academic Purposes. Malwah, NJ: Lawrence Erlbaum Associates.

Berkenkotter, Carol, Vijay J. Bhatia and Maurizio Gotti (eds.) (2012) Insights into Academic Genres. Bern: Peter Lang.

Bhatia, Vijay K. (1993) Analysing Genre: Language Use in Professional Settings. London: Longman. Bhatia, Vijay K. (2004) Worlds of Written Discourse: A Genre-based View. London: Continuum.

Bhatia, Vijay J. And Maurizio Gotti (eds.) (2006) Explorations in Specialized Genres. Bern: Peter Lang.

Canagarajah, Suresh (1999) Resisting Linguistic Imperialism in English Teaching. Oxford: Oxford University Press.

Canagarajah, Suresh (2002) A Geopolitics of Academic Writing. Pittsburgh: University of Pittsburgh Press.

Candlin, Christopher (2002) 'Alterity, Perspective and Mutuality in LSP Research and Practice'. In: Gotti, Maurizio, Dorothee Heller and Marina Dossena (eds.) Conflict and Negotiation in Specialized Texts. Bern: Peter Lang, 21-40.

Candlin, Christopher and Maurizio Gotti (eds.) 2004. Intercultural Discourse in Domain-Specific English. Special issue of Textus 17 (1), Genoa: Tilgher.

Candlin, Christopher and Maurizio Gotti (eds.) ${ }^{2}$ (2007) Intercultural Aspects of Specialized Communication. Bern: Peter Lang.

Cortese, Giuseppina and Philip Riley (eds.) (2002) Domain-specific English. Textual Practices across Communities and Classrooms. Bern: Peter Lang.

Cotterill, Janet and Anne Ife (eds.) (2001) Language across Boundaries. London: BAAL/Continuum.

D’Angelo, Larissa (2012) 'Identity Conflicts in Book Reviews: A Cross-disciplinary Comparison'. In: Gotti, Maurizio (ed.) (2012) Academic Identity Traits: A Corpus-based Investigation. Bern: Peter Lang, 79-94.

Ferguson, Gibson, Carmen Pérez-Llantada and Ramón Plo (2011) 'English as an International Language of Scientific Publication: A Study of Attitudes'. World Englishes 30 (1), 41-59. 
Flowerdew, John (ed.) (2002) Academic Discourse. Cambridge: Cambridge University Press.

Giannoni, Davide S. (2008) 'Medical Writing at the Periphery: the Case of Italian Journal Editorials'. Journal of English for Academic Purposes 7 (2), 97-107.

Giannoni, Davide S. (2012) 'Local/Global Identities and the Medical Editorial Genre'. In: Gotti, Maurizio (ed.) (2012) Academic Identity Traits: A Corpus-based Investigation. Bern: Peter Lang, 59-78.

Gotti, Maurizio (ed.) (2012) Academic Identity Traits: A Corpus-based Investigation. Bern: Peter Lang.

Gotti, Maurizio, Dorothee Heller and Marina Dossena (eds.) (2002) Conflict and Negotiation in Specialized Texts. Bern: Peter Lang.

Gunnarsson, Britt-Louise (2000) 'Swedish Tomorrow: A Product of the Linguistic Dominance of English?' Current Issues in Language and Society 7, 51-69.

Harris, Sandra (1984) 'Questions as a Mode of Control in Magistrates' Courts'. International Journal of the Sociology of Language 49, 5-28.

Hyland, Ken (2000) Disciplinary Discourses. Social Interactions in Academic Writing. London: Longman.

Kachru, Yamuna (2009) 'Academic Writing in World Englishes: The Asian Context'. In: Murata, Kumiko and Jennifer Jenkins (eds.) Global Englishes in Asian Contexts. Basingstoke: PalgraveMacmillan, 111-130.

Kandiah, Thiru (2005) 'Academic Writing and Global Inequality: Resistance, Betrayal and Responsibility in Scholarship'. Language in Society 34 (1), 117-132.

Maci, Stefania M. (2012) 'The Discussion Section of Medical Research Articles: A Cross-cultural Perspective'. In: Gotti, Maurizio (ed.) (2012) Academic Identity Traits: A Corpus-based Investigation. Bern: Peter Lang, 95-120.

Mauranen, Anna (1993) Cultural Differences in Academic Rhetoric: A Text Linguistic Study. Frankfurt am Main: Peter Lang.

Pascual, Esther (2002) Imaginary Trialogues: Conceptual Blending and Fictive Interaction in Criminal Courts. Utrecht: LOT Dissertation Series 68.

Pascual, Esther (2006) 'Questions in Legal Monologues: Fictive Interaction as Argumentative Strategy in a Murder Trial'. Text \& Talk 26 (3), 383-402.

Rowley-Jolivet, Elizabeth and Shirley Carter-Thomas (2005) 'Genre Awareness and Rhetorical Appropriacy: Manipulation of Information Structure by NS and NNS Scientists in the International Conference Setting'. English for Specific Purposes 24, 41-64.

Sala, Michele (2012) 'Different Systems, Different Styles: Legal Expertise and Professional Identities in Legal Research Articles'. In: Gotti, Maurizio (ed.) (2012) Academic Identity Traits: A Corpus-based Investigation. Bern: Peter Lang, 121-141.

Salager-Meyer, Françoise, Maria Ángeles Alcaraz Ariza and Nahirana Zambrano (2003) 'The Scimitar, the Dagger and the Glove: Intercultural Differences in the Rhetoric of Criticism in Spanish, French and English Medical Discourse (1930-1995)'. English for Specific Purposes 22, 223-247.

Scollon, Ron and Suzanne Wong Scollon (1995) Intercultural Communication: A Discourse Approach. Oxford: Blackwell.

Swales, John (1990) Genre Analysis. English in Academic and Research Settings. Cambridge: Cambridge University Press.

Swales, John (1997) 'English as Tyrannosaurus Rex’. World Englishes 16, 373-382.

Swales, John (2004) Research Genres: Exploration and Applications. Cambridge: Cambridge University Press.

Thompson, Geoff (2001) 'Interaction in Academic Writing: Learning to Argue with the Reader'. Applied Linguistics 22 (1), 58-78.

Yakhontova, Tatyana (2001) 'Textbooks, Contexts, and Learners'. English for Specific Purposes 20, 397-415.

Zamel, Vivian and Ruth Spack (eds.) (2001) Negotiating Academic Literacies. Mahwa, NJ: Lawrence Erlbaum. 
Maurizio Gotтr is Professor of English Language and Translation and Director of the Research Centre on Specialized Languages (CERLIS) at the University of Bergamo. His main research areas are the features and origins of specialized discourse (Robert Boyle and the Language of Science, Guerini, 1996; Specialized Discourse: Linguistic Features and Changing Conventions, Peter Lang, 2003; Investigating Specialized Discourse, Peter Lang, ${ }^{3} 2011$ ). He is a member of the Editorial Board of national and international journals, and edits the Linguistic Insights series for Peter Lang.

Address: Prof. Maurizio Gotti, Università di Bergamo, Piazza Rosate 2, 24129 Bergamo, Italy. [email: m.gotti@unibg.it] 